\title{
Educação para pensar questões socioambientais e qualidade de vida
}

\section{Education for think about social- environmental issues and quality of life}

\author{
Sonia Buck* \\ Andreia Aparecida Marin**
}

\begin{abstract}
RESUMO
A análise das relações entre educação e condições de saúde nos grandes centros urbanos está definitivamente atrelada às questões socioambientais. Pensar qualidade de vida significa pensar qualidade ambiental e desenvolver ações preventivas de saúde pressupõe voltar olhos para o crescimento urbano. O presente trabalho trata da causalidade de condições de baixa qualidade de vida e saúde advinda das mudanças de paisagem e problemas ambientais associados ao crescimento urbano desordenado. Apresenta ainda uma análise crítica dos condicionantes da acomodação em situações de inadequação ambiental e baixa qualidade de vida, apontando para possíveis formas como a educação ambiental pode significar o instrumento pelo qual a comunidade se abra à reflexão sobre o lugar habitado e o tratamento das questões socioambientais nele vivenciadas. As bases para pensar essa educação passam pela abordagem crítica e sócioconstrutivista e os pressupostos da educação ambiental.

Palavras-chave: educação ambiental, fundamentos socioambientais, qualidade de vida.
\end{abstract}

* Doutora em Ciências Biológicas (USP). Professora do Departamento de Teoria e Fundamentos da Educação da Universidade Federal do Paraná. E-mail: sbuck@ufpr.br

** Doutora em Ecologia e Recursos Naturais (UFSCAR). Professora do Departamento de Teoria e Práticas de Ensino da Universidade Federal do Paraná. E-mail: aamarin@ufpr.br 


\begin{abstract}
The analysis between education and quality oh life in the large urban centers is definitely connected to social-environmental issues. Thinking about the quality of life is considering the environmental quality and to develop health prevention actions that will presuppose to turn the attention to the planning of urban growth. This present work will deal with the casualty of low conditions in the quality of life and health that comes from alterations in the environment and their problems that are associated with the uncontrolled urban growth. It will also present a critical analysis for the conditions of accommodation in situations of environmental inadequacies that will be the instrument used by the community to open itself up to the reflection about the occupied habitat and the treatment of the socialenvironmental issues experienced there. The basis to think about this education will include a critical and social-constructive approach and the establishment of environmental education.

Key-words: environmental education, social and environmental foundations, quality of life.
\end{abstract}

\title{
Introdução
}

O crescimento urbano desordenado, acompanhado das mudanças bruscas na paisagem, tem como efeito tanto a perda de referenciais da relação do ser humano com o lugar, e conseqüente empobrecimento da sua cultura e identidade, quanto o prejuízo direto via impactos ambientais. As derivações desses quadros formados são implicações na qualidade ambiental e de vida das comunidades humanas e, conseqüentemente, das suas condições de saúde.

A organização da produção e do trabalho, visando atender as metas desse crescimento, acaba por renegar a segundo plano a educação e a interação social, esferas de fundamental importância para a formação humana e da coletividade.

Tendo como base a problematização sobre a relação entre desenvolvimento e questões socioambientais, o presente trabalho é iniciado com a apresentação do panorama da crise socioambiental que enfrentamos na atualidade. Na seqüência, é buscado o entendimento de como algumas políticas sociais acabam por reafirmar a situação posta, à medida que se nutrem da política 
de mercado e não atentam para a necessidade de organização da sociedade para o trato dos problemas por ela vividos. Partindo, então, do pressuposto de que só por meio de uma transformação nas formas de organização social é possível se chegar à solução dos problemas socioambientais, parte-se para uma defesa da emergência de uma educação crítica que desperte o sentido da análise crítica e do associativismo. Sob essa tendência, procura-se repensar a essência da educação ambiental e de algumas práticas pedagógicas vinculadas à criação de novas concepções de mundo e de interação social.

\section{Panorama da crise socioambiental urbana}

O desenvolvimento e o modo de produção mundial estão caminhando para um quadro de utilização irracional dos recursos naturais, originando exaustão de elementos indispensáveis à manutenção da vida e contribuindo para a baixa qualidade de vida humana.

Nas últimas décadas, a questão socioambiental vem despertando preocupações e crescente interesse social, uma vez que se torna pano de fundo para a compreensão das complexas relações que estabelecem a vida no planeta. A questão ambiental engloba um conjunto de interações internas ao sistema social e deste com o ambiente caracterizadas segundo Lima (1999, p. 135) como situações marcadas pelo conflito, esgotamento e destrutividade que se expressam nos limites materiais ao crescimento econômico exponencial; na expansão urbana e demográfica; na tendência ao esgotamento de recursos naturais e energéticos não renováveis; no crescimento acentuado das desigualdades socioeconômicas intra e internacionais, que alimentam e tornam crônicos os processos de exclusão social; no avanço do desemprego estrutural; na perda da biodiversidade e na contaminação crescente dos ecossistemas terrestres, entre outros. Todas as situações mencionadas comprometem a qualidade de vida humana. Ainda segundo Lima (1999, p. 135): "a questão ambiental revela o retrato de uma crise pluridimensional que aponta para a exaustão de um determinado modelo de sociedade que produz, desproporcionalmente, mais problemas que soluções...”.

Muitos estudiosos do ambiente urbano apontam a necessidade do entendimento de cidades sob uma ótica que integre o sítio natural, a materialidade urbana e as atividades humanas, sob pontos de vista mais holísticos, em uma dimensão evolutiva. Segundo Mendonça (2001, p. 82), a intensificação das 
preocupações com o ambiente urbano deriva, dentre outros fatores, do incremento das cidades no que diz respeito ao seu crescimento e complexidade, fato aliado ao aumento da queda da qualidade de vida urbana.

O conceito de qualidade de vida abrange as condições nas quais vivem os indivíduos no trabalho, em sua casa e na cidade. Ela está, portanto, relacionada às coisas, direitos, sentimentos que são vivenciadas no cotidiano. Recentemente tem havido uma tendência clara a considerar que qualidade de vida é tudo que possa proporcionar uma vida melhor. As condições de saúde, renda, educação, nutrição, moradia, lazer, segurança, auto-realização das pessoas são alguns dos fatores determinantes na qualidade de vida humana (HERCUlano, 1998, p. 93).

Para Coelho (2001, p. 35) a compreensão sobre os problemas urbanos impactos ambientais, como processo, depende, sobretudo de se compreender a história (não-linear) de sua produção, o modelo de desenvolvimento urbano e os padrões sociais internos.

Fatores como aumento da industrialização, produção, circulação e consumo de mercadorias, e o constante aumento populacional nas cidades que se intensificou nos dois últimos séculos, promoveram a explosão urbana, introduzindo paulatinamente a degradação de seus ambientes.

os problemas ambientais (ecológicos e sociais) não atingem igualmente todo o espaço urbano. Atingem muito mais os espaços físicos menos favorecidos do que os das classes mais elevadas. A distribuição espacial das primeiras está associada à desvalorização de espaço, quer pela proximidade dos leitos de inundação dos rios, das indústrias, quer pela insalubridade, tanto pelos riscos ambientais como desmoronamento e erosão (COELHO, 2001, p. 27).

Ainda, segundo Lima (2003, p. 114), a acelerada intervenção humana na natureza, os desequilíbrios ecológicos e a degradação da qualidade de vida são temas por demais em destaque. Os problemas ecológicos e de pobreza são resultados do modelo de desenvolvimento adotado, sendo essencial a busca de um estilo de desenvolvimento desejável à preservação da vida no planeta. 


\section{Políticas socioambientais}

Os discursos ambientalistas têm em sua gênese e evolução a proposta de desenvolvimento como possibilidade de equidade social e adequação ambiental. Trata-se do já tão discutido desenvolvimento sustentável que, ao localizar-se entre as malhas do próprio sistema que motivou sua necessidade - o capitalismo -, acaba por perder-se entre efeitos da sujeição à economia de mercado e ao ideal neoliberalista.

A sustentabilidade tem no seu cerne uma importante questão levantada por Demo (2002, p. 15): quer ser uma alternativa ao capitalismo ou uma alternativa ao desenvolvimento? O modelo ecologicamente correto é uma adaptação da exploração ambiental ao sistema de capital, por exemplo, nas muitas vezes em que tem como meta reduzida a certificação ambiental de grandes grupos concentradores de renda, revelando clara contradição ao discurso de responsabilidade social de seu plano essencial. A que conceito de desenvolvimento está, portanto, atrelado, o discurso da sustentabilidade?

O fato é que os problemas socioambientais cada vez mais apontam para o paradoxo de adaptar-se a um sistema que tem como condicionante o avesso dos pressupostos do discurso ambientalista. Talvez possam ser vistos, neste contexto, como um dos fatores que, historicamente, serão responsáveis pela implosão de um sistema que não mais responde pelas necessidades emergentes, a partir do aparecimento contextual de organização e convivência social e de alternativas de produção econômica.

Logicamente que, para dar sustentação a essa mudança histórica são necessárias algumas condições construídas, como uma sociedade organizada, politizada e capaz de análises críticas sobre as situações vividas. No contexto das nossas reflexões, precisa ser uma sociedade capaz de pensar sua qualidade ambiental e de vida e dizer quais as condições que julga ideais, traçando como meta coletiva às mudanças necessárias. Em suma, uma sociedade que não aceita o assistencialismo e a punição como forma de solução de seus problemas, exigindo para si o direito de participação e de emancipação.

...embora a assistência seja direito radical de sobrevivência, quando voltada sobre si mesma, torna-se fantástica arapuca assistencialista: além de não resolver a sobrevivência material, por conta da dependência perversa aí embutida e dos resíduos repassados, cultiva a pobreza política, 
à medida que prende o pobre a esquemas de marginalização insuperável e o faz típica massa de manobra (DEMO, 2002, p. 17).

Demo nos apresenta severas críticas ao assistencialismo que sempre prevê os "mínimos sociais", que sequer satisfazem às necessidades de sobrevivência, e potencializam a inércia dos marginalizados e a sua infantilização política. Entre os alvos da política dos "mínimos", inscrita no que chama de "hermenêutica das emergências", está a saúde e a educação. A política social voltada para a questão da saúde precisa necessariamente estar ancorada na perspectiva de uma política socioambiental preventiva e a política educacional numa dimensão de educação crítica e sócio-construtivista.

As questões de saúde não são resolvidas pelas ações emergenciais, afloradas das denúncias de condições sub-humanas, mas de um profundo entendimento de suas relações com os impactos socioambientais advindos do desenvolvimento desordenado e da perda efetiva de qualidade ambiental e de vida. Na medida em que exige essa análise complexa, demanda a participação popular no sentido de apontar para condições inapropriadas vivenciadas nos seus espaços habitados, pensar possibilidades de mudança e exigir do Estado a parcela de responsabilidade que lhe diz respeito. Isso reflete o verdadeiro princípio da democracia, na medida em que dá à sociedade o papel de controladora do Estado, via associativismo, invertendo a comum relação de supremacia estatal, que hoje vemos tanto no trato das questões ambientais quanto nas políticas assistencialistas.

Alguns caminhos são apontados como promissores para o estabelecimento de outros paradigmas de desenvolvimento humano, e neles o papel da Educação é amplamente reforçado, no sentido de como poderá contribuir para modificar a situação do planeta. Segundo Carrera (1994, p. 21), recentes estudos ligados à Organização das Nações Unidas (ONU) dedicados à questão ambiental indicam, em primeiro lugar, a necessidade de haver uma difusão de informação por meio dos sistemas formais e informais de educação para que as políticas e providências necessárias à sobrevivência e bem-estar das diferentes sociedades do mundo possam ser explicadas e entendidas. Em segundo lugar, mostram que comunidades organizadas e bem informadas podem contribuir em muito para decisões que as afetam diretamente e, ao mesmo tempo, desempenhar um papel indispensável na criação de uma sociedade segura e sustentável. Recomendam ainda que todo esse processo de formação deve buscar a ética mundial para a vida sustentável por meio da ação em todos os setores da sociedade. 


\section{Assistencialismo versus gestão participativa}

A pobreza política que se nutre no assistencialismo permite também que iniciativas de organização popular, como as expressas pelo terceiro setor, sejam vistas pelas comunidades assistidas também como ações protecionistas. Em adição, infelizmente, muitas das ONGs, em especial ambientalistas, ou são criadas com objetivos adversos ao atendimento da necessidade de emancipação na solução das questões socioambientais, ou acabam também por se perder em discursos vinculados à economia de mercado, visando tão somente a transmissão de parcela do poder do Estado para si.

A origem dos movimentos de organização social no cenário nacional remonta do período das transições democráticas no final dos anos setenta. A democracia direta e participativa foi, segundo Gohn (2002, p. 312), uma busca de autonomia em reação ao regime militar. Qualidade de vida e meio ambiente foram um dos pilares sobre os quais ganharam força essas iniciativas. Os direitos sociais, mais diretamente relativos às condições de trabalho, educação e saúde, vão ganhar maior ênfase, segundo a autora, com a relevância do conceito de cidadania, no universo das forças políticas organizadas ao longo dos anos noventa. As organizações começam, nesse contexto de lutas político-sociais, a se revelar como gestores na prestação de serviços sociais, trabalhando em favor dos marginalizados, o que evidencia a estratificação da sociedade. Segundo Gohn (2002, p. 320), os "vulneráveis" representam, nesse arranjo político, "fontes de capital social" desde que organizados pelos "ativistas" que, portanto, se transformam em "empreendedores" que organizam a comunidade em função de desenvolver formas alternativas de produção. É o grande momento de destaque do ambientalismo empresarial. Vê-se, assim, que no lugar de estar a serviço da construção de identidades culturais e coletividades atuantes, tais organizações passam a reproduzir o papel imperativo e a visão mercadológica do Estado.

É preciso, portanto, repensarmos o papel de toda e qualquer associação no amadurecimento da consciência sociopolítica-ambiental. Para tanto, precisamos, mais do que nunca, resgatar os princípios da educação crítica, colocando o conhecimento como instrumento da formação política e do exercício de pensar a coletividade.

Demo (2000, p. 19) nos aponta que “(...) seria difícil não perceber que o futuro da qualidade de vida estará muito mais marcado pela inclusão do conhecimento do que da assistência". Nesse sentido, ele coloca a importância da educação, não como via de inserção no mercado, mas como oportunidade 
de desenvolvimento da politicidade que tem como pressuposto saber pensar e intervir na busca da qualidade de vida, como instrumento de empowerment das comunidades subjugadas. Logicamente, essa educação voltada para a emancipação deve também se ocupar de não reproduzir, nas metas de desenvolvimento humano, valores próprios da acumulação de capital advindos da ideologia globalizante. Deve, portanto, estar voltada para a equidade social e para a eticidade que reforça o sentido da coletividade e da partilha do bem comum.

Antes, porém, de adentrarmos nas reflexões sobre a dimensão da educação voltada para a qualidade ambiental e de vida, é importante que pensemos mais a relação entre conhecimento e poder de emancipação.

Foucault (1996, p. 141-142) aponta para os sutis meios de dominação exercidos sobre os cidadãos na modernidade, que reprimem a percepção das necessidades de movimentos libertadores. Para transpor esse tipo de repressão não manifesta, o conhecimento é de suma importância, na medida em que desperta o poder: “(...) o exercício do poder cria perpetuamente saber e, inversamente, o saber acarreta efeito de poder (...) Não é possível que o poder se exerça sem saber, não é possível que o saber não engendre poder".

A educação que se volta para a mudança precisa, portanto, ser uma educação que desperte o conhecimento sobre as malhas do poder e como ele é exercido. Uma comunidade que sabe os condicionantes a que está submetida, que consegue refletir as relações entre mecanismo de exercício de poder e seus efeitos na qualidade ambiental e de vida, está preparada para associar-se na busca de soluções. Se em nossas propostas de educação ambiental, estamos restritos ao fornecimento de informações pontuais e técnicas sobre determinado problema socioambiental, estamos deixando de educar para o empowerment. Nossas ações precisam se voltar para um pensar muito mais complexo, de maneira que motivemos os diálogos sobre as questões que representam efetivamente a gênese desses problemas pontuais, dimensão em que as comunidades se percebam como parte das relações de poder, portanto com direito a também exercê-lo.

O poder funciona e se exerce em rede. Nas suas malhas os indivíduos não só circulam, mas estão sempre em posição de exercer esse poder e de sofrer sua ação, nunca são o alvo inerte e consentido do poder, são sempre centros de transmissão (FOUCAULT, 1996, p. 183). 
A educação ambiental deve representar o início de um processo que oportunize a participação das comunidades nas decisões sobre os problemas socioambientais, instrumentalizando-as para a gestão participativa dos bens ambientais. Ocorre que, em muitos casos, a gestão participativa tem significado um modo de governantes abrirem o espaço público para uma população não preparada para a participação. Isso acaba por significar tão somente uma transferência de responsabilidade sem transferência de poder. Em nossos dias, as propagandas políticas, ao mesmo tempo em que fazem uso das propostas de gestão democrática participativa, vêm acompanhadas do ranço assistencialista, contradição clara, já que uma proposta exige amadurecimento político enquanto outra a reafirmação da desmobilização. Mais uma vez, é preciso que atentemos para a necessidade da educação ambiental não perder seu objetivo mais fundamental: o de trabalhar a essência da interação ser humano-natureza e as relações entre saber-poder expressas na vida coletiva.

\section{Para uma educação que desperte o olhar sobre si e seu lugar}

O universo das relações entre educação, saúde e trabalho revela-se um intrincado campo de investigação para se pensar políticas socioambientais adequadas. As três dimensões se conectam, na contemporaneidade, por um viés ideológico claramente ancorado na ligação capital-poder: a educação, ao reproduzir valores e características de uma sociedade de consumo, colocando-se a serviço da formação para o mercado de trabalho; a saúde, por ser diretamente afetada por estas metas e por modelos inadequados de uso de bens naturais; o trabalho, ao ser encarado unicamente como via de ascensão econômica individual.

Cidadania é uma questão formativa, educativa de largo alcance. Uma cidadania real deve refletir um paradigma existencial, do existir na coletividade, com dignidade sócio-político-cultural de uma pessoa, que para ser alcançada, exige uma alfabetização social (...) Promover acesso ao conhecimento, numa dimensão educativa, é realizar uma potencialização histórica e humana de uma sociedade (VIEIRA, 1999, p. 152 , grifos do autor). 
Habermas (1980, p. 318) nos aponta como dois eixos da atividade humana o trabalho e a interação social, levantando uma clara intervenção das finalidades do trabalho na esfera da interação, o que traz conseqüências políticas diretas expressas na tecnocracia e despolitização. Habermas também recorta a necessidade de se deslocar o interesse do trabalho e da produção na relação do ser humano com a natureza para a esfera da interatividade:

Em vez da natureza explorada, podemos ir a busca da natureza fraterna. Numa subjetividade ainda incompleta, podemos atribuir subjetividade aos animais, às plantas e até mesmo às pedras e comunicar-nos com a natureza, em vez de nos limitarmos a trabalha-la, quebrando a comunicação (...) Só se os homens pudessem se comunicar sem coação e se cada homem pudesse reconhecer-se no outro, só então a espécie humana poderia eventualmente reconhecer a natureza como outro sujeito... (HABERMAS, 1980, p. 318).

Mergulhada na esfera do trabalho, quer seja por condição de sobrevivência ou acúmulo de capital, a sociedade não encontra tempo e significado para exercer a coletividade. Desse mergulho brotam: a falta de percepção de problemas claros, mesmo daqueles que fazem parte de seu cotidiano, como a maioria dos problemas ambientais; a sujeição à diminuição da qualidade de vida, e conseqüente comprometimento da saúde; a falta de abertura ao outro e de oportunidades de mobilização, dentre outros.

$\mathrm{O}$ pensamento crítico, que se desenvolveu no século $\mathrm{XX}$, opunha-se à função dessa educação capitalista de reprodução da sociedade e à toda ação pedagógica voltada para a imposição arbitrária da cultura das classes dominantes. Ele encontra na chamada Escola de Frankfurt um dos seus referenciais mais importantes.

A educação no contexto de domínio cultural é, segundo Palanca (2001, p. 46), uma educação reduzida à formação de produtores e consumidores potenciais, conseqüência de uma economia de mercado, onde tudo se converte em mercadoria - até mesmo o homem e seu trabalho. Nos dias de hoje, as minorias ativas estão representadas por uma parcela das populações humanas que consegue resistir aos mecanismos de dominação, repressão, e manipulação do sistema. Elas são destacadas por Horkheimer (1991, p. 157), juntamente com os intelectuais, como segmentos políticos fundamentais para a transformação social. 
Segundo Maar (1995, p. 63), a implantação dos sistemas nacionais de ensino confere à escola o papel de transmitir e conservar a cultura e os conhecimentos universais, bem como formar o cidadão para atuar na sociedade, privilegiando a fragmentação do saber e o seu atrelamento ao interesse de grupos sociais detentores de poder, dentro de uma lógica positivista. A teoria crítica fornece à educação uma ruptura com esse padrão e um vínculo com a realidade social, tornando o processo pedagógico um processo crítico e emancipatório. Também nesse sentido, para Rondon (2001, p. 218), a escola, apesar de sua fragilidade diante da realidade, tem a tarefa de possibilitar educação que alcance a emancipação dos seres humanos.

Partindo-se da perspectiva crítica, a educação ambiental não deve ser reduzida à transmissão de um corpo de conhecimentos sobre ambiente e saúde, embora a informação seja fator indispensável. Uma educação ambiental crítica implica, como nos diz Gaudiano (1997, p. 11), não só em dotar os sujeitos de instrumentos intelectuais para decodificar, desconstruir, fazer suas próprias interpretações da realidade, mas para facilitar sua incorporação a uma nova construção social.

Loureiro (1997, p. 148) nos fala que os grupos sociais possuem peculiaridades ligadas à situação particular de seus ambientes e à percepção qualitativa dos problemas, destacando as classes populares como sendo as mais atingidas pelas dificuldades oriundas do processo de degradação da qualidade de vida, seja pela marginalização cultural e social sofrida, seja pela distribuição desigual dos bens materiais. Nessa perspectiva, coloca a preocupação de que a educação ambiental medre, diante do grande desafio de transformar tal situação, transformando-se em simples modismo atrelado aos discursos ambientalistas.

Entre os pressupostos da educação ambiental expressos pela Unesco (1976) estão o vínculo do educando com a realidade vivida pela comunidade de que faz parte e o desenvolvimento de valores que o motive a perceber a necessidade de transformação dessa realidade, quer ela envolva problemas ambientais ou sociais. Dessa forma, a educação ambiental é um instrumento importantíssimo para a necessária mudança de valores da modernidade para os de justiça social e equilíbrio com a natureza, tendo a participação como seu princípio básico. Deve, assim, ser um processo participativo por meio do qual o indivíduo e a coletividade constroem valores sociais, adquirem conhecimentos, tomam atitudes, exercem habilidades voltadas para a conquista da qualidade de vida e ambiental no espaço habitado, num contexto de justiça social. 


\section{Para uma educação voltada para outra concepção de mundo}

Os governos podem assinar tratados, podem adotar a Carta da Terra, porém não cumprirão suas promessas se a sociedade civil não estiver vigilante e capacitada para pressionar os governantes para que eles cumpram o que assumiram.

Neste contexto é que surge o papel da Escola como ambiente catalisador de mudanças, de discussões, aprendizado na área das questões socioambientais. Segundo Gadotti (2000, p. 22) todas as escolas podem tornar-se palco para grandes transformações, ensinando ideais democráticos: conexão, escolha, responsabilidade, decisão, iniciativa, igualdade, biodiversidade, cores, classes, etnicidade e gênero.

A questão do meio ambiente começa a surgir como uma variável para o processo educativo a partir da Conferência de Estocolmo, em 1972. Aparecendo, primeiramente, como área de estudos das ciências naturais, a Educação Ambiental foi sendo considerada, aos poucos, elemento primordial para uma educação voltada à participação e resolução ativa dos problemas.

Apesar do Brasil ser signatário de importantes documentos produzidos durante todas as conferências internacionais, algumas dessas mobilizações em defesa do meio ambiente e da Educação Ambiental vão refletir-se nas formulações, mas, nem sempre, na efetivação das políticas nacionais.

A Constituição Brasileira, aprovada em 1988, dedica um capítulo especial à questão ambiental, admitindo a Educação Ambiental como um importante instrumento da Política Nacional de Meio Ambiente e reconhecendo que cabe ao poder público sua promoção em todos os níveis de ensino. Desde então, os governos estaduais e municipais começam a perceber a necessidade de transformar a questão da Educação Ambiental em uma prioridade para as suas administrações.

Para se alcançar estes objetivos deverá ser desenvolvida a percepção e o entendimento sobre a questão ambiental a partir de novos valores e mentalidade crítica que incrementem habilidades, conhecimentos e atitudes na preservação do equilíbrio ambiental.

Toda essa problemática ambiental lança aos educadores da atualidade, o desafio de encontrar, em suas práticas pedagógicas, caminhos por meio dos quais se possam formar gerações ecologicamente mais sensíveis.

Neste contexto, e aliado ao fato da formação dos professores contemplar as questões ambientais de maneira superficial, não tendo como foco principal de suas ações a problemática socioambiental e tratando o assunto de 
forma periférica, observamos na escola contemporânea trabalhos de educação ambiental com práticas às vezes consideradas simplistas, reducionistas, que refletem confusão teórica (RAMOs, 2001, p. 212; LIMA, 2003, p. 110).

Lima (2003, p. 109) comenta que nas últimas décadas trabalhos de educação ambiental em escola não apresentaram resultados esperados no atendimento às complexas relações socioambientais e que para avançar neste sentido faz-se necessária uma nova abordagem, sendo que as mudanças desejadas exigem um novo paradigma integrador - ou holístico - que os educadores ambientais não conseguiram ainda colocar em prática.

Alguns autores apontam para a necessidade de uma abordagem mais espiritualista e holística na educação (HUTCHISON, 2000, p. 65) e a repercussão deste enfoque em um efetivo cuidar do ambiente e do ser humano (BOFF, 2000, p. 101). Segundo Boff, nossa civilização precisa superar o modelo existente que nos mantém reféns de uma lógica que hoje se mostra destrutiva para a Terra e seus bens.

A abordagem crítica, que defendemos como forma de se atingir essa superação em comunidades, pode ser pensada como uma base estrutural importante também para a educação ambiental formal. Existem, no entanto, nessa dimensão educativa, outras tendências promissoras baseadas, por exemplo, na ecopedagogia, na ecologia profunda e na antroposofia. Nessa última, podemos contextualizar a Pedagogia Waldorf, criada no início do século XIX por Rudolf Steiner, que compreende uma forma educativa alternativa, autêntica e humanista que se preocupa em possibilitar à criança, desde seu primeiro contato com a escola, uma integração profunda com a natureza (IGNÁcio, 1995, p. 29). As bases teóricas para essa Pedagogia encontram-se na Antroposofia: caminho de conhecimento que orienta diferentes áreas com sua visão espiritualizada do ser humano (LANZ, 1986, p. 11).

Uma das características da Antroposofia, no que diz respeito à sua aplicação pedagógica, é a preocupação com a formação moral do indivíduo, que deve ser desenvolvida de maneira intensa, baseada em um amor altruísta e não na imposição de uma obrigação pessoal. A moralidade segundo o princípio Antroposófico estende-se ao respeito profundo a todos os seres vivos e ao universo. Segundo Steiner, esta moralidade deve ser desenvolvida por meio do conhecimento pleno e veneração da natureza (STEINER, 2003, p. 86).

$\mathrm{Na}$ escola Waldorf o trabalhado pedagógico segue um direcionamento de intencionalidades minucioso, que diferencia o universo escolar em que são aplicados, dos objetos utilizados todos 100\% naturais (HUTCHISON, 2000, p. 139) à postura do professor. O cotidiano escolar apresenta simplicidade, coerência e numerosas formas de se estimular e exercitar o contato da criança 
com a natureza (IGNACIO, 1995, p. 29). Outros elementos presentes nas escolas Waldorf contribuem para a formação de princípios ecologicamente sensíveis nas crianças: o trabalho intimamente ligado com os ritmos e ciclos da natureza, a veneração ao Meio Ambiente e a atitude não consumista exemplificada diariamente pelos professores.

$\mathrm{Na}$ área da Educação, este trabalho pedagógico traz ao educador uma abordagem inovadora. Os laços que a criança Waldorf adquire com o meio natural se formam naturalmente, elemento que a grande maioria das crianças destas escolas tendem a manter, durante toda a vida, criando uma posição de veneração, admiração e proteção da natureza, ainda que nenhuma das fases escolares Waldorf contenha uma matéria denominada "Educação Ambiental”.

\section{Considerações finais}

Os pontos de vista apresentados não pretendem encerrar as discussões frente às complexas relações sobre educação e às questões socioambientais, pelo contrário, mostram-se como caminhos que devem ser percorridos motivados pela procura de novos olhares, discussões, reflexões, e sensibilidade para perceber os conflitos da sociedade e os limites do ambiente natural.

A crença no paradigma do desenvolvimento econômico de um país desvinculado do bem-estar social da sua população e também descomprometido com o ambiente natural vem sendo cada vez mais desacreditado.

Os caminhos da educação voltada ao ambiente ainda não têm receitas ou regras estipuladas e definidas. É um eterno andar, construindo-se, ao mesmo tempo, o caminho. Cabe a nós estarmos atentos a novas práticas pedagógicas, a novas posturas frente à questão socioambiental.

Os estudos que enfocam a qualidade de vida, especialmente na área da saúde, apontam para a necessidade de formulação de políticas públicas comprometidas com a relação socioambiental, associadas a projetos educacionais que em última instância integram a população neste trabalho conjunto. A construção de uma sociedade justa, capaz de oferecer qualidade de vida digna para a sua população e defender os seus bens naturais, certamente passa pelo trabalho educacional que se volta a entender o seu ambiente em todos os seus aspectos: social, biológico, cultural, étnico e econômico. 


\section{REFERÊNCIAS}

BOFF, L. Saber cuidar: ética do humano - compaixão pela terra. Petrópolis: Vozes, 2000 .

CARRERA, A. C. S. A educação matemática e a questão ambiental. Temas e Debates, Sociedade Brasileira de Educação Matemática, v. 5, p. 21-28, 1994.

COELHO, M. C. N. Impactos ambientais em áreas urbanas - teorias, conceitos e métodos de pesquisa. In: GUERRA, A. J. T.; CUNHA, S. B. (Orgs.). Impactos ambientais urbanos no Brasil. Rio de Janeiro: Bertrand Brasil, 2001.

DEMO, P. Política social do conhecimento - sobre futuros do combate à pobreza. Petrópolis: Vozes, 2000.

. Novos paradigmas em política social. In: CARVALHO, D. B. B.; SOUZA, N. H. B.; DEMO, P. (Orgs). Novos paradigmas da política social. Brasília: UnB, 2002. FOUCAULT, M. Microfisica do poder. 11. ed. Rio de Janeiro: Graal, 1996.

GADOTTI, M. Pedagogia da Terra. 3. ed. São Paulo: Fundação Peirópolis, 2000.

GAUDIANO, E. G. Educación ambiental: historia u conceptos a veinte anos de Tbilisi. México: Sistemas Técnicos de Edición, 1997.

GOHN, M. da G. Políticas públicas e sociedade civil no Brasil nas últimas décadas. In: CARVALHO, D. B. B.; SOUZA, N. H. B.; DEMO, P. (Orgs). Novos paradigmas da politica social. Brasília: UnB, 2002.

HABERMAS, J. Técnica e ciência enquanto ideologia. In: BENJAMIN, W. et al. Textos escolhidos. Tradução: Zeljiko Loparic e Andréa Maria Altino de Campo Loparic. São Paulo: Abril Cultural, 1980. p. 313-343. (Os Pensadores).

HERCULANO, S. C. A qualidade de vida e seus indicadores. Ambiente e Sociedade, ano 1, n. 2, p. 77-99, 1998.

HORKHEIMER, M. Teoria tradicional e teoria crítica. São Paulo: Abril Cultural, 1991. (Os Pensadores).

HUTCHISON, D. Educação ecológica - idéias sobre consciência ambiental. Porto Alegre: Artes Médicas Sul, 2000.

IGNÁCIO, R. K. Criança querida - o dia-a-dia das creches e jardim-de-infância. Associação Comunitária Monte Azul. São Paulo: Antroposófica, 1995.

LANZ, R. A Pedagogia Waldorf - caminho para um ensino mais humano. São Paulo: Antroposófica, 1986.

LIMA, G. C. Questão ambiental e educação: contribuições para o debate. Ambiente e Sociedade, ano 2, n. 5, p. 135-153, 1999. 
. O discurso da sustentabilidade e suas implicações para a educação. Ambiente e Sociedade, v. 6, n. 2, p. 99-119, 2003.

LOUREIRO, C. F. B. A educação ambiental junto às classes populares: condições teóricas e práticas essenciais para uma ação transformadora. Cadernos Pedagógicos e Culturais, Niterói, v. 6, n. 1/2, p.147-158, jan./dez. 1997.

MAAR, W. L. Educação crítica, formação cultural e emancipação política na Escola de Frankfurt. In: PUCCI, Bruno. (Org). Teoria crítica e educação: a questão da formação cultural na Escola de Frankfurt. Petrópolis: Vozes, 1995.

MENDONÇA, F. Abordagem interdisciplinar da problemática ambiental urbano-metropolitana: esboço metodológico da experiência do doutorado em MA \& D da UFPR sobre a RMC - Região Metropolitana de Curitiba. Desenvolvimento e Meio Ambiente, n. 3, p. 79-95, 2001.

PALANCA, N. Globalização: a difícil fuga do mundo administrado. In: LASTÓRIA, L. A. C. N.; COSTA, B. C. G.; PUCCI, B. Teoria crítica, ética e educação. Piracipaca/ Campinas: Unimep, 2001.

RAMOS, E. C. Educação ambiental: origem e perspectivas. Educar, n. 18, p. 201$218,2001$.

RONDON, R. Os desafios da emancipação no atual momento da educação brasileira. In: LASTÓRIA, L. A. C. N.; COSTA, B. C. G.; PUCCI, B. Teoria crítica, ética e educação. Piracipaca/Campinas: Unimep, 2001.

STEINER, R. A arte da educação II: metodologia e didática. São Paulo: Antroposófica. 2003.

UNESCO. Taller Subregional de educación ambiental para educación secundaria. Chosica, 1976.

VIEIRA, A. F. Mobilidade social, educação e poder no Brasil. Contato, Brasília, ano 1, n. 3, abr./jun. 1999.

Texto recebido em 03 fev. 2005

Texto aprovado em 28 mar. 2005 